\title{
A tool to measure work adjustment in the post-pandemic economy: The Illinois work adjustment scale
}

\author{
David R. Strauser ${ }^{\mathrm{a}, *}$, Chelsea E. Greco ${ }^{\mathrm{a}}$, John F. Koscuilek ${ }^{\mathrm{a}}$, Sa Shen ${ }^{\mathrm{a}}$, \\ D. George Strauser ${ }^{\mathrm{a}}$ and Brian N. Phillips ${ }^{\mathrm{b}}$ \\ ${ }^{a}$ University of Illinois at Urbana-Champaign, Champaign, IL, USA \\ ${ }^{\mathrm{b}}$ Utah State University, Logan, UT, USA
}

Received 27 March 2020

Accepted 22 October 2020

\begin{abstract}
.
OBJECTIVE: This article introduces the Illinois Work Adjustment Scale (IWAS) and sets out to confirm the internal validity of the IWAS as well as determine if there are meaningful dimensions among the items of the IWAS that can be further defined as instrument subscales.

METHODS: In order to meet these objectives, a survey of 738 individuals, all of whom self-reported as having disabilities, was conducted online.

RESULTS: As a result of this survey and exploratory and confirmatory factor analyses, the IWAS was reduced from a 26question scale to an 18-question scale consisting of two meaningful subscales, Work Context and Work Capacity. Significant and meaningful correlations between the two subscales indicate that Work Context and Work Capacity are related to the broader concept of work adjustment and assess unique aspects of work.

CONCLUSION: The IWAS has the potential to be applied to facilitate positive career development and vocational rehabilitation outcomes for people with disabilities and chronic health conditions. This is of greater importance now as the COVID-19 crisis has significantly impacted the economy and workforce, leaving those with the greatest barriers to employment such as individuals with disabilities and chronic health conditions further marginalized and disconnected from work.
\end{abstract}

Keywords: COVID-19, Illinois, work capacity, work context, employment, pandemic

\section{Introduction}

Modern work environments are characterized by quickly changing cognitive and social demands that require an individual to adjust by developing or strengthening abilities to meet the changing demands of work (Strauser, 2021). This changing nature of work and the consequent need to develop new skills and abilities are especially relevant for displaced,

\footnotetext{
*Address for correspondence: David R. Strauser, Department of Kinesiology and Community Health, University of Illinois, 1206 South Fourth Street, Champaign, IL 61820, USA. Tel.: +1 217244 3936; E-mail: strauser@illinois.edu.
}

marginalized workers, including individuals with disabilities, given the negative economic impact that COVID-19 has had, and will continue to have, on the labor market. As a result of the pandemic, over seventeen million individuals have been displaced or detached from the labor market in the United States, with individuals with chronic health conditions and disabilities being disproportionately impacted (Soucheray, 2020). Many of the individuals displaced were working in service sector positions that are not conducive to alternative work formats, resulting in a significant reduction or permanent loss of employment. Additionally, front line health care workers are being put at risk on a daily basis for developing 
significant physical and psychological injuries and permanent disabilities from providing services to those hospitalized due to COVID-19. Furthermore, non-medical frontline workers such as grocery store cashiers and employees of other essential businesses, are also placed at risk for obtaining COVID-19, increasing their chances of developing acute and future chronic health conditions that place them at an increased probability of having to miss work due to illness and permanent job loss (Kantamneni, 2020).

As a result of the interaction of the increased number of individuals becoming disconnected from the labor market, increased risk of developing physical and psychological chronic health conditions through work, and the dynamic nature of work and the work environment, there will be a significant increase in the need for career and vocational services to assist individuals in reentering the labor market post COVID-19 (Kantamneni, 2020). Given the anticipated loss of entry level service sector positions, the changing nature of how work is being performed (remote vs. in person), and the need to prepare people with chronic health conditions for more complex and interpersonally demanding positions, there should be a renewed focus on the concept of work adjustment as part of career and vocational services directed at labor market re-entry. Taking a career development approach with an increased focus on work adjustment, there is a need for a contemporary, brief and easy to administer scale that accounts for both the physical and psychological components of work in the broader post-pandemic work environment. This article provides an introduction to the Illinois Work Adjustment Scale (IWAS) as a potential tool that can be used in career and vocational interventions and planning to help facilitate labor market reentry of those displaced by COVID-19.

\subsection{Theoretical background}

Historically, the term "work adjustment" has been used in vocational rehabilitation (VR) to refer to the process and activities that individuals employ to maintain congruence between themselves and the work environment. Work adjustment is viewed as the key factor in maintaining employment and has historically been viewed as one of the most important VR services available to individuals with disabilities to improve employment outcomes (Strauser, Wagner, Wong, \& O'Sullivan, 2013; Wright, 1980). Two major work adjustment theories that have received considerable attention in the vocational rehabilitation literature are the Minnesota Theory of Work Adjustment (MTWA) and Hershenson's Model of Work Adjustment (Brown \& Lent, 2004; Dawis, 2005; Hershenson, 1981; Parker \& Szymanski, 2005). While there are notable differences regarding the conceptualization of work adjustment, the key principle guiding both theoretical models is the importance of establishing and maintaining congruence between the person and her or his work environment (Dawis, 2005; Dawis \& Lofquist, 1984). In addition to the useful explanatory structure offered by these models, it is also important for VR practitioners to consider the psychological processes that lead individuals to participate in vocationally-driven activities and influence their perceptions regarding meeting the demands of the work environment. For example, self-efficacy theory has been applied to explain an individual's motivation, with increased levels of self-efficacy being associated with better vocational outcomes (Bandura, 1986; Lent, Morrison, \& Ezeofor, 2013).

Historically in VR, work adjustment services have focused on establishing congruence between the individual and the work environment through promoting the acquisition of satisfactory work habits, increasing one's physical and emotional capacity for meeting the physical and emotional demands of the work environment, and addressing attitudes and behaviors that might limit that satisfactory performance of work (Wright, 1980). Work adjustment is not an innate trait, but rather a learned attribute, culminating from the socialization process that begins at birth, in which the family, social, and educational environments play a critical role in the acquisition of appropriate behavioral, emotional, and motivational traits that an individual needs to become a productive individual and is manifested in one's work personality (Strauser, Waldrop, \& Ketz, 1999; Wright, 1980). To increase work personality and achieve the goal of increased congruence, work adjustment services are directed at both improving physical tolerance and addressing the psychological factors such as selfconfidence, self-control, social skills, and confidence in one's ability to meet the demands of changing work environments (Strauser et al., 2013).

In today's contemporary vocational rehabilitation service model, people are no longer referred to formal work adjustment training programs to strengthen work adjustment. Despite the lack of formal work adjustment training programs, increasing an individual's work adjustment is still a main focus of VR services. For example, in commonly used place and 
train models of job placement, such as supported or customized employment, issues related to work adjustment are typically addressed through the provision of on and off the job site employment supports (Wehman et al., 2018). In working with transition age youth with disabilities, the Workforce Innovation and Opportunity Act (WIOA) specifies that pre-employment transition services should include workplace readiness training that focuses on preparing youth for the challenges of work through training in soft skills, customer service, work place communication, accessing transportation, and self-advocacy (Workforce Innovation Technical Assistance Center, 2016).

Given the importance of work adjustment in improving employment outcomes, it would appear to be important for VR counselors to have a theoretically-based brief instrument to measure an individual's perceived confidence in engaging in important work adjustment activities. The purpose of the current study was to construct an instrument, the Illinois Work Adjustment Scale (IWAS), that has both clinical and research applications regarding the work adjustment of individuals with disabilities. Utilizing self-efficacy theory as a guide, we based the construction of the instrument on the core elements of the major theories of work adjustment (i.e., Minnesota Theory of Work Adjustment, Hershenson's Model), and input from practitioners and researchers with VR expertise and clinical experience. The present article presents the results of a study that was undertaken to empirically derive and examine the factorial structure of the IWAS. Specifically, the following research questions guided our study:

1. Can meaningful dimensions be identified among items of the Illinois Work Adjustment Scale (IWAS), which can then be defined as instrument subscales?

2. Do the IWAS subscales show adequate internal consistency?

\section{Method}

\subsection{Procedures}

Human subjects' approval for this project was granted from the University of Illinois at UrbanaChampaign Institutional Review Board. Participants were recruited using a combination of the crowdsourcing data collection tools Amazon Mechanical Turk (MTurk) and TurkPrime. MTurk is used by thousands of researchers to obtain sample participants while TurkPrime provides a more user-friendly interface and additional options for data collection. Potential participants who had previously identified as having a disability or chronic health condition were offered an opportunity to participate in the study through MTurk and were administered the survey online via Qualtrics. Individuals who completed the survey received a $\$ 15.00$ incentive payment. Participants were informed that their participation was voluntary and that they were free to withdraw at any time without negatively impacting received services. Upon completion of the survey, participants were provided a unique participant ID that was utilized only to be able to pay the participants and was not stored with the survey data. No individual identifying information tying the subjects to their results was retained with the data.

\subsection{Participants}

The sample consisted of 738 U.S. adults living with a disability or chronic health condition. The sample population included only people with disabilities and chronic health conditions as the aim of this study was to understand how the IWAS would perform in rehabilitation settings. The mean age of participants was 43.48 years $(\mathrm{SD}=12.51$, range $=20-77)$, with $30.4 \%$ male, $69.1 \%$ female, and $0.5 \%$ other. A total of $82.2 \%$ identified as Caucasian, $8.1 \%$ as Black or African American, 3.3\% as Latino/Hispanic, 2.6\% as Asian, $0.4 \%$ as Native American/Alaskan Native, and $3.4 \%$ as other/multiple races. Highest level of education for the individuals in the sample was $0.3 \%$ with some high school, $8.8 \%$ with a high school diploma, 3.5\% with a General Education Diploma (GED), 28.9\% with some post-secondary schooling without a degree, $15.7 \%$ with an associate's degree, $30.6 \%$ with a bachelor's degree, and $12.2 \%$ with a graduate degree. At the time of the study, $41.9 \%$ of our sample was employed full-time, $14 \%$ was employed part-time, $16.7 \%$ worked contract, freelance, or temporary work, $22.9 \%$ were unemployed, and $4.6 \%$ selected Other. Finally, when asked which disability category (or categories) best describe their current functioning, $74.8 \%$ selected physical, $24.3 \%$ neurological, $55.7 \%$ psychiatric/mental health, $5.0 \%$ cognitive, $3.8 \%$ Deaf/hard of hearing, $4.9 \%$ vision impairment/blind, and $4.1 \%$ other. Table 1 provides a summary of the demographic characteristics of study participants. 
Table 1

Demographic characteristics of the participants. $(\mathrm{N}=738)$

\begin{tabular}{|c|c|}
\hline Variable & $n(\%)$ \\
\hline \multicolumn{2}{|l|}{ Gender } \\
\hline Male & $224(30.4 \%)$ \\
\hline Female & $510(69.1 \%)$ \\
\hline Other & $4(0.5 \%)$ \\
\hline \multicolumn{2}{|l|}{ Race } \\
\hline Asian & $19(2.6 \%)$ \\
\hline Black or African American & $60(8.1 \%)$ \\
\hline Hispanic/Latino & $24(3.3 \%)$ \\
\hline Native American/Alaskan Native & $3(0.4 \%)$ \\
\hline Native Hawaiian/Pacific Islander & $0(0.0 \%)$ \\
\hline White & $607(82.2 \%)$ \\
\hline Other/multiple races & $25(3.4 \%)$ \\
\hline \multicolumn{2}{|l|}{ Marital status } \\
\hline Single & $230(31.2 \%)$ \\
\hline Married & $263(35.6 \%)$ \\
\hline Cohabitating/life partner & $94(12.7 \%)$ \\
\hline Separated & $21(2.8 \%)$ \\
\hline Divorced & $103(14.0 \%)$ \\
\hline Widowed & $21(2.8 \%)$ \\
\hline Other & $6(0.8 \%)$ \\
\hline \multicolumn{2}{|l|}{ Disability category (mark all that apply)* } \\
\hline Physical & $552(74.8 \%)$ \\
\hline Neurological & $179(24.3 \%)$ \\
\hline Psychiatric/mental health & $411(55.7 \%)$ \\
\hline Cognitive & $44(6.0 \%)$ \\
\hline Deaf/hard of hearing & $28(3.8 \%)$ \\
\hline Vision impairment/blind & $36(4.9 \%)$ \\
\hline Other & $30(4.1 \%)$ \\
\hline \multicolumn{2}{|l|}{ Level of education } \\
\hline Some high school & $2(0.3 \%)$ \\
\hline High school graduate & $65(8.8 \%)$ \\
\hline GED & $26(3.5 \%)$ \\
\hline Some college & $213(28.9 \%)$ \\
\hline Associate degree & $116(15.7 \%)$ \\
\hline Bachelor's degree & $226(30.6 \%)$ \\
\hline Postgraduate degree & $90(12.2 \%)$ \\
\hline \multicolumn{2}{|l|}{ Current employment status } \\
\hline Full-time (at least 30hrs/wk) & $309(41.9 \%)$ \\
\hline Part-time & $103(14.0 \%)$ \\
\hline Contract, freelance, or temporary work & $123(16.7 \%)$ \\
\hline Unemployed (not looking for work) & $112(15.2 \%)$ \\
\hline Unemployed (looking for work) & $57(7.7 \%)$ \\
\hline Other & $34(4.6 \%)$ \\
\hline \multicolumn{2}{|l|}{ Annual household income (before taxes) } \\
\hline Less than $\$ 19,999$ & $170(23 \%)$ \\
\hline$\$ 20,000-\$ 39,999$ & $200(27.1 \%)$ \\
\hline$\$ 40,000-\$ 69,999$ & $186(25.2 \%)$ \\
\hline$\$ 70,000-\$ 89,999$ & $94(12.7 \%)$ \\
\hline$\$ 90,000-\$ 110,000$ & $39(5.3 \%)$ \\
\hline Over $\$ 110,000$ & $49(6.6 \%)$ \\
\hline
\end{tabular}

Note. Percentages may not add up to exactly 100 due to multiple responses allowed or rounding error.

\subsection{Instruments}

The Illinois Work Adjustment Scale (IWAS) was developed as a theoretically-based instrument that measures an individual's self-efficacy regarding the core elements of work adjustment. Using the MTWA
(Dawis, 2005) and Hershenson's Model of Work Adjustment (Hershenson, 1984) as a foundation to guide a comprehensive literature review focusing on work adjustment, 26 items were initially identified for scale inclusion. Those 26 items were subsequently reviewed by an expert panel of 4 individuals with knowledge in vocational counseling and work adjustment theory, experience in the delivery of work adjustment services in a community-based rehabilitation setting, and research regarding the career development and work adjustment of individuals with disabilities. Based on the review, 8 items were dropped due to poor wording and redundancy, resulting in an 18-item scale. A 10-point Likert scale was established as the rating scale for the IWAS items [(0-9) with 0 being "not confident" and 9 being "extremely confident"]. The 10-point rating scale was developed based on Bandura's (1977) recommended scale rating for measures of self-efficacy.

\subsection{Statistical analysis}

Factor analysis, including exploratory factor analysis (EFA) and confirmatory factor analysis (CFA), were used to determine and validate the underlying dimensions of the IWAS. The full sample $(N=$ 738) was first randomly split into two independent groups - training data $(N=369)$ and test data groups $(N=369)$. Training set was used to train the factor model and test set was used to test the trained model. Mplus (Muthén \& Muthen, 2017) was used to fit these models.

For the training data group, an EFA was conducted to determine the most appropriate factor structure for IWAS. Geomin rotation was used so the correlations between factors were estimated. The optimal number of factors was selected based on the eigenvalues (greater than 1), scree plot, item cross-loadings, and theoretical interpretability. Only items with factor loadings of an absolute value greater than 0.4 were retained, which would explain around $16 \%$ of the variance in the variable. Items were assigned to factors on which they loaded most highly. Items that did not load or cross-loaded on any factor were removed from further analysis.

For the test data group, a CFA within the framework of structural equation modeling was performed to confirm the factor structure determined in EFA by training data and to assess model fit. The overall model fit was examined using various absolute fit and incremental fit indices. Absolute fit indices included normed chi-square, root mean square error of 
approximation (RMSEA) and standardized root mean square residual (SRMR). Normed chi-square is defined as the ratio of chi-square and the degree of freedom in the model. Schumacker \& Lomax (2004) recommended a value less than 2 for normed chisquare for adequate model fit. RMSEA is a parsimony-adjusted index that is based on the non-centrality parameter. The RMSEA estimates the lack of fit in a model compared to a saturated model and the threshold value for an acceptable model fit is 0.08 (Browne \& Cudeck, 1993). SRMR is the square-root of the difference between the residuals of the sample covariance matrix and the hypothesized model. Values SRMR as high as 0.08 are deemed acceptable $(\mathrm{Hu}$ $\&$ Bentler, 1999). We also considered two incremental fit indices: Tucker-Lewis index (TLI), comparative fit index (CFI). Values of these indices over 0.90 represent a satisfactory model fit (Awang, 2012). After the selection of the final best-fitting model, internal consistency reliability for each factor using the full sample was determined.

\section{Results}

\subsection{Exploratory factor analysis}

Analysis was performed with 18 IWAS items on training data. Two- to five- factor models were tested to determine the optimal number of factors to retain. Eigenvalues for these factor structures were 1.88, 0.97, 068 and 0.64, respectively. Scree plot and item factor loadings in each model were also examined. The result indicated a solution of a two-factor model. All 18 items had their highest loadings on their assigned factors (see Table 2). Factor 1 including 14 items was identified as addressing issues related to Work Context. Factor 2 was comprised of 4 items and addressed items related to Work Capacity.

\subsection{Confirmatory factor analysis}

The 2-factor structure was identified to be the most appropriate for the training group with the EFA. This structure was confirmed using CFA on data from the test group. The model-fit indices of the model indicated a good fit to the data: $\chi^{2} / \mathrm{df}=$ 5.13, RMSEA $=0.10, \mathrm{CFI}=0.91, \mathrm{TLI}=0.89$ and $\mathrm{SR}$ $\mathrm{MR}=0.05$. All parameters were significant $(p<$ $0.0001)$. In addition, the two factors were positively related to each other with a significant correlation coefficient of $0.59(p<0.0001)$.

\subsection{Internal consistency}

The internal consistency reliability coefficient of each subscale was assessed by Cronbach's coefficient alpha using the whole sample. Each subscale score of the IWAS showed a very high internal consistency ( $\alpha=0.95$ for factor 1 and $\alpha=0.94$ for factor 2 ).

\section{Discussion}

The purpose of the current study was to construct and test an instrument, the Illinois Work Adjustment Scale (IWAS), that has both clinical and research applications regarding the work adjustment of individuals with disabilities. This article presents the theoretically and empirically-derived factor structure of the IWAS. Based on study sample data, the IWAS is comprised of 18 items with two meaningful subscales labeled Work Context and Work Capacity. The subscales demonstrate adequate internal consistency, providing evidence of both subscale item interrelatedness and stability. Significant and meaningful correlations between the two subscales indicate that work context and capacity are related to the broader concept of work adjustment, and assess unique aspects of work. Overall the study findings indicate good factorial structure for the 18-item IWAS with the brevity of the instrument increasing potential application and use in both research and clinical settings. Specific findings regarding the two factors are discussed in the following paragraphs.

Regarding factorial integrity, both the EFA and CFA suggest good model fit with all 18 items significantly loading on two relevant factors. Factor one, Work Context, consists of 14 items relating to an individual's ability to adjust to the demands of work in terms of both specific tasks and the interpersonal social demands related to the work environment. Specifically, the items comprising work context address how confident an individual perceives oneself in getting along with co-workers, applying personal judgment in the work environment, completing work tasks, adapting to workplace changes, and behaving appropriately in the work environment. Disability-related career development and employment research has consistently identified such areas as critical to educational and employment outcomes and a major factor contributing to poor work performance for people with disabilities (Park, Kim, \& Kim, 2016). Empirical and clinical research indicates that an individual's perceptions regarding confidence 
Table 2

Two-factor solution: Exploratory factor analysis

\begin{tabular}{|c|c|c|}
\hline \multirow[t]{2}{*}{ IWAS item } & \multicolumn{2}{|c|}{ Factor loading } \\
\hline & 1 & 2 \\
\hline \multicolumn{3}{|l|}{ Factor 1: Work Context } \\
\hline 1. I am confident about my ability to follow basic work rules. & 0.773 & -0.089 \\
\hline 2. I am confident about my ability to relate in a positive manner with co-workers. & 0.774 & -0.059 \\
\hline $\begin{array}{l}\text { 3. I am confident about my ability to use good judgment } \\
\text { in the work environment. }\end{array}$ & 0.889 & -0.083 \\
\hline $\begin{array}{l}\text { 4. I am confident about my ability to understand and remember } \\
\text { complex job instructions. }\end{array}$ & 0.705 & 0.089 \\
\hline $\begin{array}{l}\text { 5. I am confident about my ability to understand, remember, } \\
\text { and carry out simple job instructions. }\end{array}$ & 0.696 & 0.04 \\
\hline 6. I am confident about my ability to maintain my personal appearance. & 0.633 & 0.027 \\
\hline 7. I am confident about my ability to behave in an emotionally stable manner. & 0.732 & 0.073 \\
\hline 8. I am confident about my ability to demonstrate reliability. & 0.650 & 0.224 \\
\hline $\begin{array}{l}\text { 9. I am confident about my ability to accept feedback } \\
\text { from supervisors or co-workers. }\end{array}$ & 0.818 & -0.006 \\
\hline 10. I am confident about my ability to work in a team. & 0.792 & -0.057 \\
\hline 11. I am confident about my ability to adapt to workplace changes. & 0.789 & 0.038 \\
\hline 12. I am confident about my ability to prioritize tasks appropriately. & 0.782 & 0.037 \\
\hline $\begin{array}{l}\text { 13. I am confident about my ability to persist in the tasks } \\
\text { at hand despite challenges. }\end{array}$ & 0.768 & 0.081 \\
\hline $\begin{array}{l}\text { 14. I am confident about my ability to seek help } \\
\text { from a supervisor when required. }\end{array}$ & 0.795 & -0.106 \\
\hline \multicolumn{3}{|l|}{ Factor 2: Work Capacity } \\
\hline 15. I am confident about my ability to work an 8-hour day. & -0.001 & 0.911 \\
\hline 16. I am confident about my ability to work 5 days a week. & -0.007 & 0.950 \\
\hline 17. I am confident about my ability to work without excessive breaks. & 0.115 & 0.725 \\
\hline $\begin{array}{l}\text { 18. I am confident about my ability to maintain regular } \\
\text { work attendance on the job. }\end{array}$ & 0.108 & 0.778 \\
\hline
\end{tabular}

Note. $N=369$. Factor loadings $\geq|.30|$ are in bold.

in her or his ability to get along with co-workers, adapt to workplace changes, and complete work tasks relates to job tenure (Strauser et al., 2013).

Factor two, Work Capacity, consists of 4 items that address perceived confidence in meeting demands related to full-time competitive employment. Of the four items, two items address the individual's perception regarding his or her ability to work a typical workday ( 8 hours per day, 5 days per week), one item addresses working without excessive breaks, and one item address the ability to maintain regular work attendance. The Work Capacity subscale of the IWAS is particularly relevant to workers with disabilities and chronic health conditions who may have functional, stamina, and endurance limitations related to emotion, cognition, or physical performance. Specifically, recent research with young adult cancer survivors found that an individual's perception of his or her emotional and physical functioning was significantly related to the person's perception of both internal and external barriers to employment. Additionally, physical functioning was specifically related to the perception regarding the ability to maintain employment (Strauser, Chan, et al., 2019). Such findings suggest that the perception of physical functioning impacts an individual's perceptions regarding the work capacity demands to employment.

\subsection{Implications}

With the growing number of individuals with disabilities who are being displaced from the labor market as a result of COVID-19, especially in the service sector, there will be a significant need to provide career and vocational services to this group to help facilitate reentry. Given the expected decrease in entry level and lower skilled service positions, many individuals who are displaced will have to look to develop new skills and seek positions that will likely demand increased hard and soft skills. Implementing a career development perspective that focuses on work adjustment will be an important aspect of addressing the soft skills necessary in the reentry process. The IWAS can be used by practitioners to obtain important information regarding the individual's perceived confidence in addressing the contextual and capacity work adjustment issues as they relate to the evolving work environment. Although there is not 
psychometric support at this time for the IWAS to be diagnostic in nature, the factorial structure of the scale is adequate for clinical application to help facilitate personal exploration and intervention planning as it relates to overall work adjustment. The IWAS can also be used in conjunction with other career and functioning measures to examine the potential interaction between various individual and career factors that could impact the return to work process.

The IWAS can also be applied to research addressing the impact of COVID-19 on the career development and employment of people with disabilities and chronic health conditions. With the mounting evidence regarding the demographic distribution and disproportionate impact of COVID-19 on individuals from low socio-economic status, minority background, and low skilled service sector positions, it will be important for vocational and career researchers to examine the residual bio-psycho-social impact of COVID-19 as it relates to meeting the demands of work. Insights gathered from the interaction of bio-psycho-social functioning and work adjustment can help guide intervention development and implementation in the aftermath of the pandemic. Attempting to understand the longer-term impact of COVID-19 on the career development and employment process would also be critical and could provide important information as it relates to the provision of vocational rehabilitation services across the developmental continuum during and after COVID19. The Illinois Work and Well-Being Model can also be used to guide the research process with the IWAS being used to measure job maintenance and examine the individual and career factors impacting work adjustment and overall job maintenance in the COVID-19 employment environment (Strauser, Rumrill, \& Greco, 2019).

\subsection{Limitations}

Several potential limitations should be considered when interpreting the results of the study. First, while the sample was comprised of individuals with disabilities and chronic health conditions, participants may not represent all individuals with disabilities. It is likely that sample characteristics may not mirror those of individuals who are typically served through vocational rehabilitation. Moreover, the sample drawn in this study was primarily female, well educated, and employed, which differs from the general demographic of individuals with disabilities, thereby limiting the generalizability of the study findings. Additionally, the sample was limited in that cross-sectional and self-report data were obtained through an online format.

\subsection{Conclusion}

The results of this study provide initial factorial support regarding the Illinois Work Adjustment Scale as an instrument that can be used in both research and clinical settings to identify an individual's perceived confidence regarding work adjustment. The instrument consists of two subscales, Work Context and Work Capacity, measuring the demands related to work adjustment and would initially appear to have very good application to both clinical and research settings. However, more research is needed to provide additional confirmation of the factorial structure and construct validity of the scale. Future research is also needed to understand the impact of personal and environmental factors on the overall work adjustment process.

\section{Acknowledgments}

This paper was developed with support from the Vocational Rehabilitation Technical Assistance Center for Targeted Communities (VRTAC-TC or Project E3) at the Department of Rehabilitation and Disability Studies, Southern University, Baton Rouge, LA funded by the U.S. Department of Education, Rehabilitation Services Administration (Grant \# H264F15003).

The ideas, opinions, and conclusions expressed, however, are those of the authors and do not represent recommendations, endorsements, or policies of the U.S. Department of Education.

\section{Conflict of interest}

None to report.

\section{References}

Awang, Z. (2012). Research methodology and data analysis: Penerbit Universiti Teknologi MARA Press.

Bandura, A. (1977). Self-efficacy: Toward a unifying theory of behavioral change. Psychological review, 84(2), 191-215. https://doi.org/10.1037/0033-295X.84.2.191

Bandura, A. (1986). Social foundations of thought and action. Prentice Hall. 
Brown, S. D., \& Lent, R. W. (2004). Career development and counseling: Putting theory and research to work. John Wiley $\&$ Sons.

Browne, M. W., \& Cudeck, R. (1993). Alternative ways of assessing model fit. In K.A. Bollen \& J. S. Long (Eds.), Testing structural equation models (pp. 136-162). Sage.

Dawis, R. V. (2005). The Minnesota theory of work adjustment. Career Development, 1.

Dawis, R. V., \& Lofquist, L. H. (1984). A psychological theory of work adjustment: An individual-differences model and its applications: University of Minnesota Press.

Hershenson, D. B. (1981). Work adjustment, disability, and the three R's of vocational rehabilitation: A conceptual model. Rehabilitation Counseling Bulletin, 25(2), 91-97.

Hershenson, D. B. (1984). Vocational counseling with learning disabled adults. Journal of Rehabilitation, 50(2), 40.

Hu, L. t., \& Bentler, P. M. (1999). Cutoff criteria for fit indexes in covariance structure analysis: Conventional criteria versus new alternatives. Structural Equation Modeling: A Multidisciplinary Journal, 6(1), 1-55. https://doi.org/ 10.1080/10705519909540118

Kantamneni, N. (2020). The impact of the COVID-19 pandemic on marginalized populations in the United States: A research agenda. Journal of Vocational Behavior, 119, 103439. https://doi.org/10.1016/j.jvb.2020.103439

Lent, R. W., Morrison, M. A., \& Ezeofor, I. (2013). The career development of people with disabilities: A social cognitive perspective. In D. R. Strauser (Ed.), Career development, employment and disability in rehabilitation (pp. 113-124). Springer Publishing Company.

Muthén, L. K., \& Muthen, B. (2017). Mplus user's guide: Statistical analysis with latent variables, user's guide. Muthén \& Muthén.

Park, E.-Y., Kim, J., \& Kim, S.-S. (2016). Meta-analysis of the effect of job-related social skill training for secondary students with disabilities. Journal of Vocational Rehabilitation, 44(1), 123-133. https://doi.org/10.3233/JVR-150785

Parker, R., \& Szymanski, E. (2005). Rehabilitation counseling: Basics and beyond (4th ed.) Pro-Ed.
Schumacker, R. E., \& Lomax, R. G. (2004). A beginner's guide to structural equation modeling. Psychology Press.

Soucheray, S. (2020). US job losses due to COVID-19 highest since Great Depression. Retrieved from https://www.cidrap. umn.edu/news-perspective/2020/05/us-job-losses-due-covid19-highest-great-depression

Strauser, D. R. (2021). Introduction to the centrality of work for indviduals with disabilties. In D. R. Strauser (Ed.), Career Development, Employment, and Disability in Rehabilitation (2nd ed.). Springer Publishing Company.

Strauser, D. R., Chan, F., Fine, E., Iwanaga, K., Greco, C., \& Liptak, C. (2019). Development of the perceived barriers scale: A new instrument identifying barriers to career development and employment for young adult survivors of pediatric CNS tumors. Journal of Cancer Survivorship, 13(1), 1-9.

Strauser, D. R., Rumrill Jr, P. D., \& Greco, C. (2019). Applying the Illinois work and well-being model to increase labor force participation among people with multiple sclerosis. Journal of Vocational Rehabilitation, 51(1), 11-20.

Strauser, D. R., Wagner, S., Wong, A. W., \& O'Sullivan, D. (2013). Career readiness, developmental work personality and age of onset in young adult central nervous system survivors. Disability and Rehabilitation, 35(7), 543-550.

Strauser, D. R., Waldrop, D. G., \& Ketz, K. (1999). Reconceptualizing the work personality. Rehabilitation Counseling Bulletin, 42(4), 290-301.

Wehman, P., Taylor, J., Brooke, V., Avellone, L., Whittenburg, H., Ham, W., Brooke, A. M., \& Carr, S. (2018). Toward competitive employment for persons with intellectual and developmental disabilities: What progress have we made and where do we need to go. Research and Practice for Persons with Severe Disabilities, 43(3), 131-144. https://doi.org/ 10.1177/1540796918777730

Workforce Innovation Technical Assistance Center. (2016). Preemployment transition services Retrieved from http://www. wintac.org/topic-areas/pre-employment-transition-services

Wright, G. N. (1980). Total rehabilitation. Little and Brown. 